\title{
Status of Advanced Stitched Unitized Composite Aircraft Structures
}

\author{
Dawn Jegley ${ }^{1}$ \\ NASA Langley Research Center, Hampton, VA 23681 \\ Alex Velicki \\ Boeing Research and Technology, Seal Beach CA 90740
}

\begin{abstract}
NASA has created the Environmentally Responsible Aviation (ERA) Project to explore and document the feasibility, benefits and technical risk of advanced vehicle configurations and enabling technologies that will reduce the impact of aviation on the environment. A critical aspect of this pursuit is the development of a lighter, more robust airframe that will enable the introduction of unconventional aircraft configurations that have higher lift-to-drag ratios, reduced drag, and lower community noise levels. The primary structural concept being developed under the ERA project in the Airframe Technology element is the Pultruded Rod Stitched Efficient Unitized Structure (PRSEUS) concept. This paper describes how researchers at NASA and The Boeing Company are working together to develop fundamental PRSEUS technologies that could someday be implemented on a transport size aircraft with high aspect ratio wings or unconventional shapes such as a hybrid wing body airplane design.
\end{abstract}

\section{Introduction}

$\mathrm{N}$ ASA has created the Environmentally Responsible Aviation (ERA) Project to explore the feasibility, benefits, and technical risk of advanced vehicle configurations and enabling technologies that will reduce the impact of aviation on the environment. A critical aspect of this pursuit is the development of a lighter, more robust airframe that can enable the introduction of unconventional aircraft configurations that have higher lift-to-drag ratios, reduced drag, and lower community noise levels. In the first phase of the ERA project (2010-2012), the primary aircraft configuration considered was the Hybrid Wing Body (HWB) where the main challenge was creating a non-circular pressure cabin design that is not only lightweight but also economical to produce.

To begin addressing this fundamental constraint, researchers have worked to refine a new structural concept called the Pultruded Rod Stitched Efficient Unitized Structure (PRSEUS). Throughout Phase I of ERA, NASA and Boeing engineers have developed fundamental PRSEUS technologies that could someday be implemented on a future transport-size airframe. In ERA Phase II (2013-2015), along with a broader emphasis beyond HWB, the PRSEUS concept is being developed and validated through the design, analysis and testing of a 30 -foot long multi-bay pressure box test article that represents a portion of the HWB centerbody. Although PRSEUS is an enabling technology for the HWB airframe, its superior structural performance can also be utilized to reduce airframe weight for nearer term airplane applications with higher aspect ratio wings and circular fuselage cabins.

\section{HWB Structural Concept Development}

While the HWB planform provides many aerodynamic advantages, the noncircular shape represents a substantial weight penalty that even the most highly efficient composite material systems used on today's

\footnotetext{
${ }^{1}$ Senior Aerospace Engineer, Structural Mechanics and Concepts Branch, Associate Fellow, AIAA.

${ }^{2}$ Principal Design Engineer, The Boeing Company, Advanced Structures R\&D, Senior Member, AIAA.
} 
state-of-the-art aircraft would not be adequate to overcome. Particularly, in the pressure cabin regions that are primarily driven by out-of-plane loading considerations, any traditional layered material system would require thousands of mechanical attachments to suppress delaminations and to join structural elements, ultimately leading to fastener pull-through problems in the thin gauge skins. The other argument against a conventional composite solution is the high manufacturing costs associated with the highly contoured airframe. Not only will complex outer moldline tooling be needed, but all of the interior stringers and frame members would require individual toolsets which would adversely affect the affordability. The essential characteristics of a more capable HWB structural solution is one that operates effectively in out-of-plane loading scenarios, while simultaneously meeting the demanding producibility requirements inherent in building a highly contoured airframe.

In addition to the secondary bending stresses experienced during pressurization of the near-flat geometry, another key difference in the shell is the unique bi-axial loading pattern that occurs during maneuver loading conditions. For the HWB, the load magnitudes are more nearly equal in each in-plane direction $(\mathrm{Nx}$ and $\mathrm{Ny}$ ) than what is typically found on conventional tube-and-wing fuselage arrangements where the cantilevered fuselage is more highly loaded in the $\mathrm{Nx}$ direction, along the stringer, than in the $\mathrm{Ny}$ direction, along the frame. This single difference has a profound effect on the structural concept selection because it dictates that the optimum panel geometry should have continuous load paths in both directions ( $\mathrm{Nx}$ and $\mathrm{Ny}$ ), in addition to efficiently transmitting internal pressure loads (Nz) for the near-flat panel geometry as shown in figure 1. Additionally, for a conventional skin-stringer-frame built-up panel, the frame shear clip member is typically discontinuous to allow the stringer to pass through uninterrupted in the primary longitudinal loading direction. If such an arrangement were used for the HWB, the frame member (attached by a discontinuous shear clip to the skin) would be less effective in bending and axial loading than a continuous frame design that is attached directly to the skin, ultimately resulting in a noncompetitive solution.

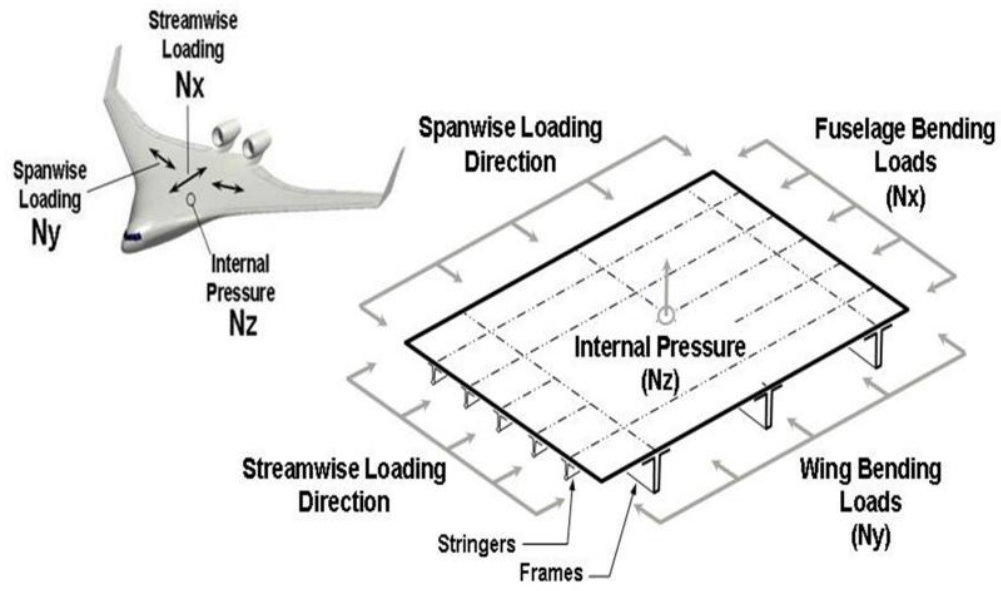

Figure 1. Combined loading on HWB pressure cabin.

To overcome these problems, an improved HWB fuselage panel should be designed as a bi-directionally stiffened panel, where the wing bending loads are carried by the frame members and the fuselage bending loads are carried by the stringers. Additionally, the panel design should also include continuous loads paths in both directions, stringer and frame laminates that are highly tailored, thin skins designed to operate well into the post-buckled design regime, and crack-stopping features designed to minimize damage propagation. Capturing such improvements is necessary to overcome the inherent weight penalties of the HWB non-circular pressure cabin.

\section{PRSEUS Concept}

The PRSEUS design and fabrication approach incorporates these design features, resulting in a highly effective structural concept. It is a conscious progression away from conventional laminated and bonded methods of assembly, and has evolved to become a one-piece cocured panel design with seamless transitions and damage-arrest interfaces. The highly integrated nature of the PRSEUS stiffened panel 
design is enabled by the use of through-thickness stitching, which ultimately leads to unprecedented levels of fiber tailoring and structural optimization potential.

The dry warp-knit fabric, pre-cured rods, and foam-core materials are assembled and then stitched together to create the PRSEUS structural geometry, as shown in figure 2. Load path continuity at the stringer-frame intersection is maintained in both directions by passing the rod-stringer through a small keyhole in the frame web. The pultruded rod increases local strength/stability of the stringer section while simultaneously shifting the neutral axis away from the skin to further enhance the overall panel bending capability. Frame elements are placed directly on the IML skin surface and are designed to take advantage of carbon fiber tailoring by placing bending and shear-conducive lay-ups where they are most effective. The stitching is used to suppress out-of-plane failure modes, which enables a higher degree of fiber tailoring than would be possible using conventional laminated materials. The resulting bi-directionally stiffened panel design is ideal for the HWB pressure cabin because it is not only highly efficient in all three loading directions, but is also stitched to react pull-off loading and enhance panel survivability. These features should also be advantageous for conventional fuselage and wing primary structure applications.

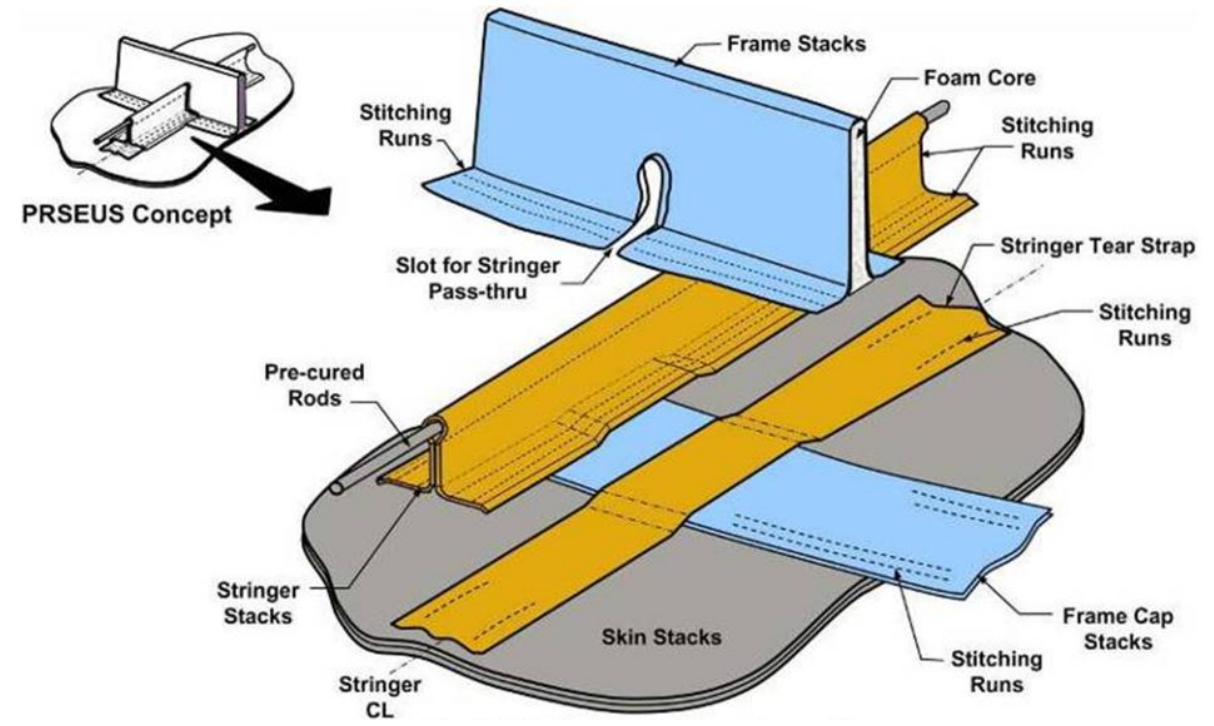

Figure 2. Exploded view of Pultruded Rod Stitched Efficient Unitized Structure (PRSEUS) concept.

While such attributes are essential for improving performance, the producibility goals cannot be ignored. The fundamental breakthrough is the self-supporting stitched preform assembly that can be fabricated without exacting tolerances, and then accurately net molded in a single oven-cure operation using high-precision outer moldline tooling. The interior surface of a cured PRSEUS panel is shown in figure 3. Since all of the materials in the stitched assembly are dry, there are no out-time or autoclave limitations as in prepreg systems, which can restrict the size of an assembly because it must be cured within a limited processing envelope. Resin infusion is accomplished using a soft tooled fabrication method where the bagging film conforms to the inner moldline surface of the preform geometry and seals against a rigid OML tool, thus eliminating costly internal tooling that would normally be required to form netmolded details. The description of the manufacture of multiple PRSEUS panels is presented in References 1-4. The fabrication of these panels proved that the essential feature of this concept, the self-supporting preform that eliminates interior mold tooling, was feasible for the near-flat geometry of the HWB airframe.

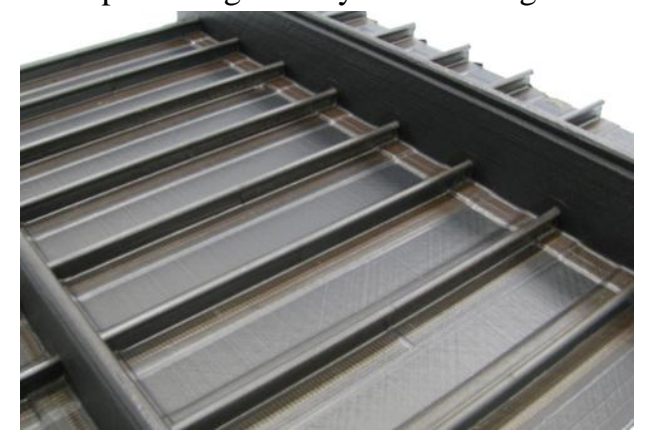

Figure 3. Interior surface of PRSEUS panel. 


\section{Structural Feasibility Testing}

A building block approach was employed to evaluate PRSEUS attributes under representative HWB pressure cabin loading conditions. Specimen sizing and load levels were derived from a series of finite element-analysis-based trade studies that calculated panel geometries and internal loading distributions for a baseline set of airplane requirements. Initial element-level testing was performed to assess the basic structural response of the PRSEUS frame and stringer elements under static and fatigue loading scenarios. Once those results verified the structural integrity of the panel architecture, a more complex set of subcomponent tests was performed to begin addressing the flat panel response under fundamental HWB fuselage loading conditions. Three large subcomponent test specimens were designed and tested to measure the panel response in these three critical loading directions, as well as generate failure load levels that could be used to calibrate the panel sizing results and airframe weights generated in the trade studies. The test results are summarized in figure 4 . To begin addressing the challenging three-dimensional aspects of the flat-sided design, a cube-shaped test article was constructed of PRSEUS panels and then joined together to create a pressure-tight unit that could be internally pressurized to simulate the $2 \mathrm{P}$ static loading condition (18.4 psi internal pressure) for the fuselage. Additional small-scale tests have also been completed but are not discussed herein.
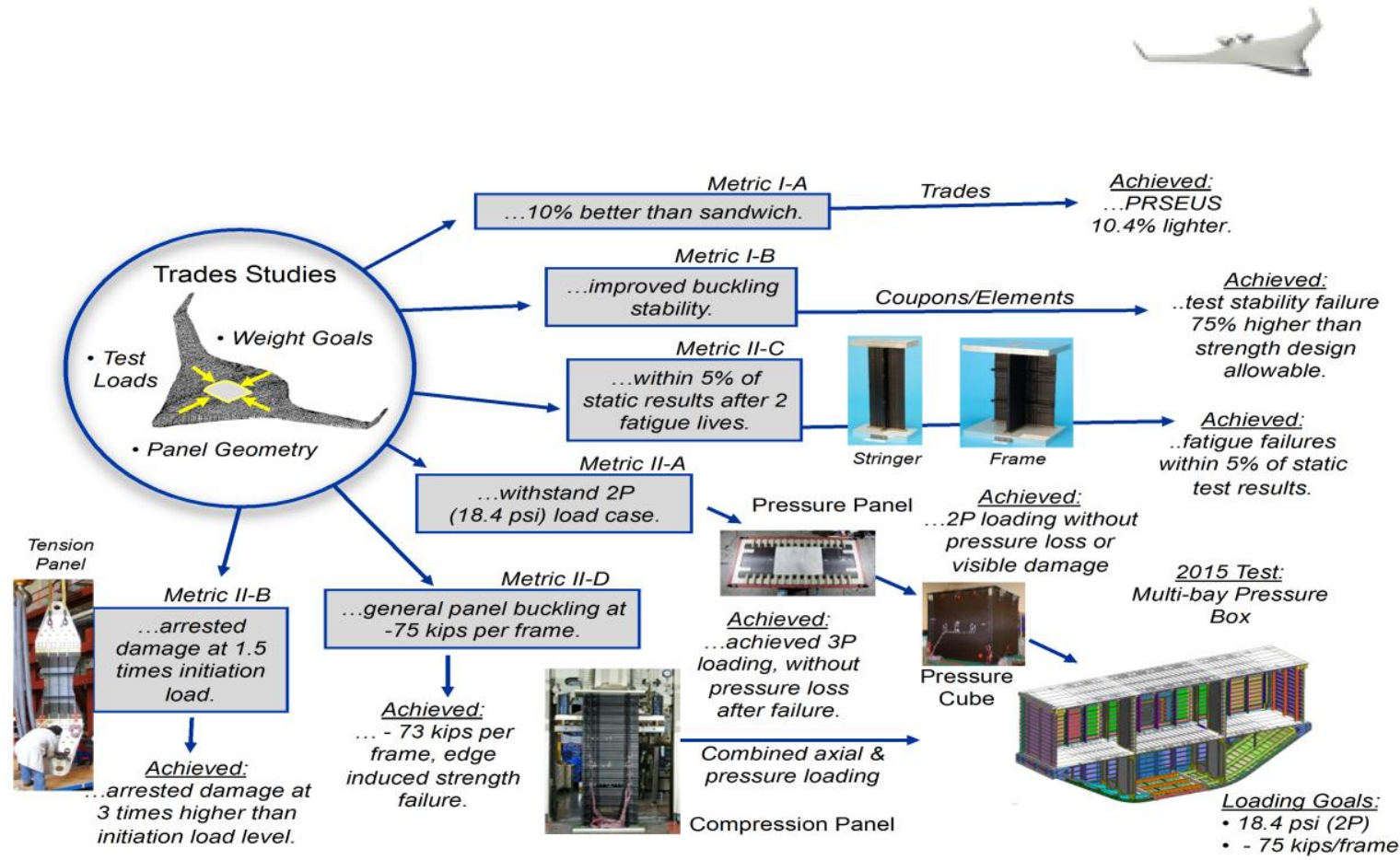

Figure 4. Pressure cabin feasibility testing approach leading to multi-bay test article.

The results from all of the panel and cube tests were then used to design a final representative proof-ofconcept test article that would be capable of simulating the unique HWB combined-loads condition. To accomplish this, a large-scale, multi-bay test article was necessary to accurately replicate the internal pressure plus maneuver loading condition that occurs during the $2.5 \mathrm{~g}$ flight maneuver condition. Such a test article is currently under development and will be tested in the future to validate the initial premise of whether the PRSEUS structural concept is capable of meeting the stringent airframe performance and producibility goals necessary to successfully enable a next-generation, lifting-body architecture like that of the HWB aircraft. 


\section{A. Coupons and Elements}

Numerous coupons and single-stiffener specimens have been tested throughout PRSEUS development with the Air Force Research Lab, Boeing and NASA (Ref 1-6). Coupons and simple elements are used to determine material properties, better understand PRSEUS response to impact damage, evaluate fatigue behavior and evaluate stress concentrations. However, these studies will not be discussed herein.

\section{B. Flat panels}

Under the NASA Subsonic Fixed Wing Program (2007-2009) and ERA Phase I (2010-2012), element and panel evaluations have been conducted. Specifically, flat unidirectionally loaded tension, compression and pressure panels were considered as representative of the acreage area of the HWB. These panels were initially evaluated to verify the fundamental assumptions about the behavior and failure modes of PRSEUS structure. Photographs of unidirectionally loaded panels are shown in figure 5 and are described in references 4,7 , and 8 . In all cases, the structures withstood the design requirements and analytical results agreed well with test data. In addition, under ERA Phase I, considerations of cabin noise and repair technologies were explored and are described in references 9 and 10, respectively. Due to engine placement on the HWB planform, noise transmission from the engines could potentially add extra weight to the cabin structure and was also studied. This parasitic weight is being evaluated by NASA in the Structural Acoustics Loads and Transmission (SALT) facility. A photograph of a PRSEUS panel in the SALT test window is shown in figure 6a. Additionally, repairability must be part of any aircraft development process. A PRSEUS test panel with a damaged and repaired center stringer is shown in figure $6 \mathrm{~b}$ prior to testing.

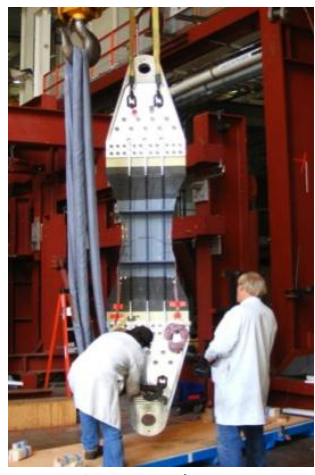

a) Tension

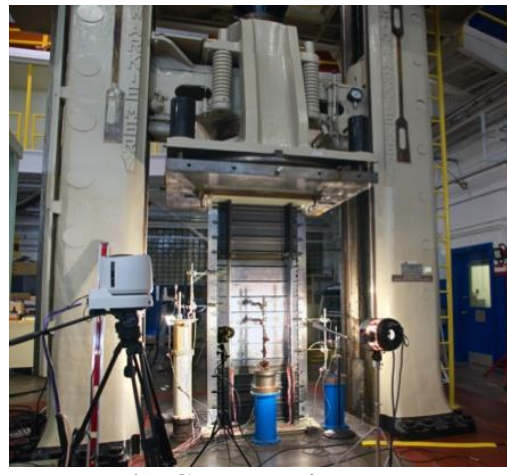

b) Compression

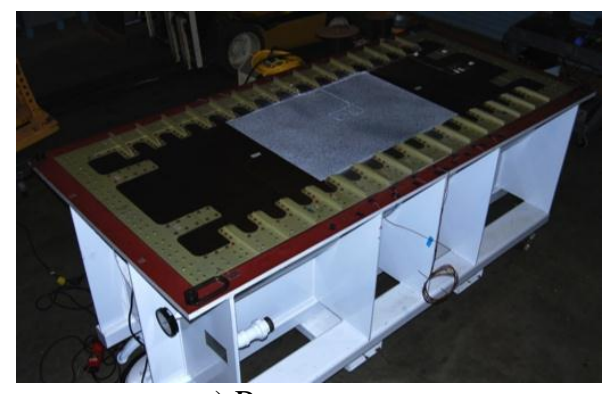

c) Pressure

Figure 5. Fundamental PRSEUS evaluation panels.

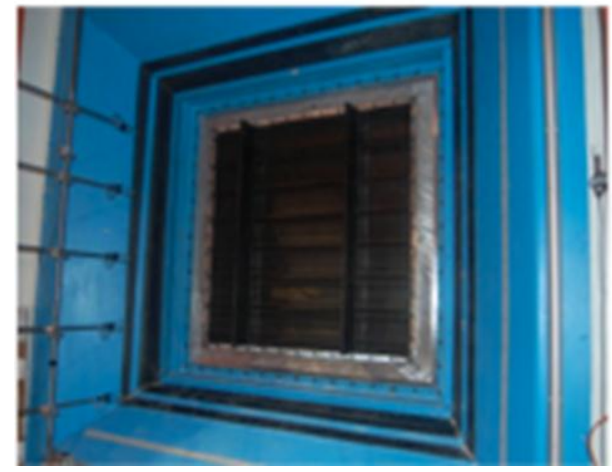

a) PRSEUS panel in the NASA SALT facility

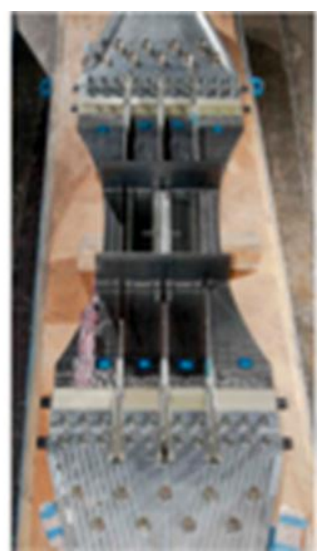

b) PRSEUS repair panel

Figure 6. Supporting technologies validation elements 


\section{Built-Up Structure and Combined Loadings}

A curved 90-inch radius PRSEUS panel representative of a traditional barrel fuselage panel is shown in figure 7 and is described in references 11 and 12. This panel was loaded in combined pressure and tension at the FAA Full-Scale Aircraft Structural Test Evaluation and Research Facility (FASTER) to demonstrate PRSEUS applicability to barrel fuselage sections. The panel (figure 7) sustained the required loads in both the pristine and damaged conditions. To assess three-dimensional effects, the cube specimen (figure 8) was pressurized to more than the required $2 \mathrm{P}$ (18.4 psi) loading condition to examine the behavior of joined PRSEUS panels, as described in reference 13.

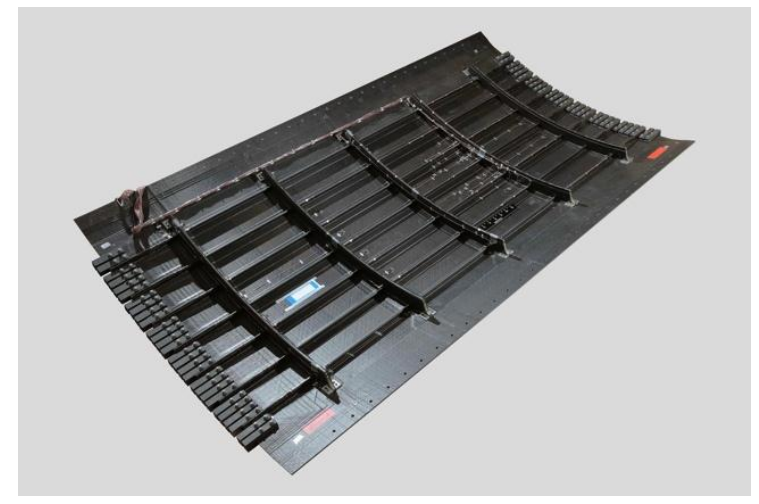

Figure 7. PRSEUS curved panel.

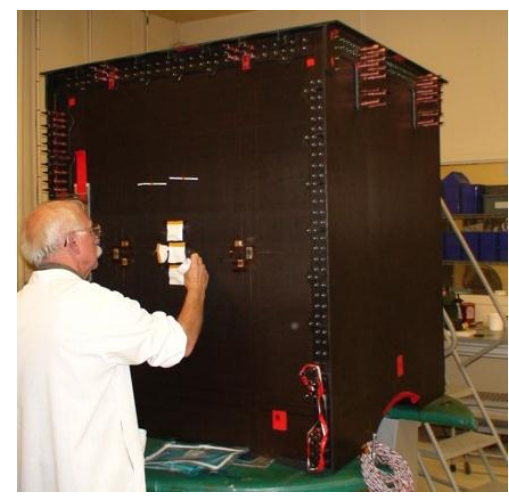

Figure 8. PRSEUS cube specimen.

\section{Large Scale Multi-Bay Test Article}

The next step in PRSEUS development is being conducted in ERA Phase II where a 30-foot-long multibay test article is being constructed. The test article is representative of a portion of the center section of a HWB vehicle but addresses the same construction, analysis and pressurization issues that would be encountered on a traditional airframe. These technologies include minimum-gauge design, post-buckled skins, crack arrestment, impact damage, manufacturing scale-up to larger structures, and joining technologies. A sketch of the multi-bay test article is shown in figure 9.

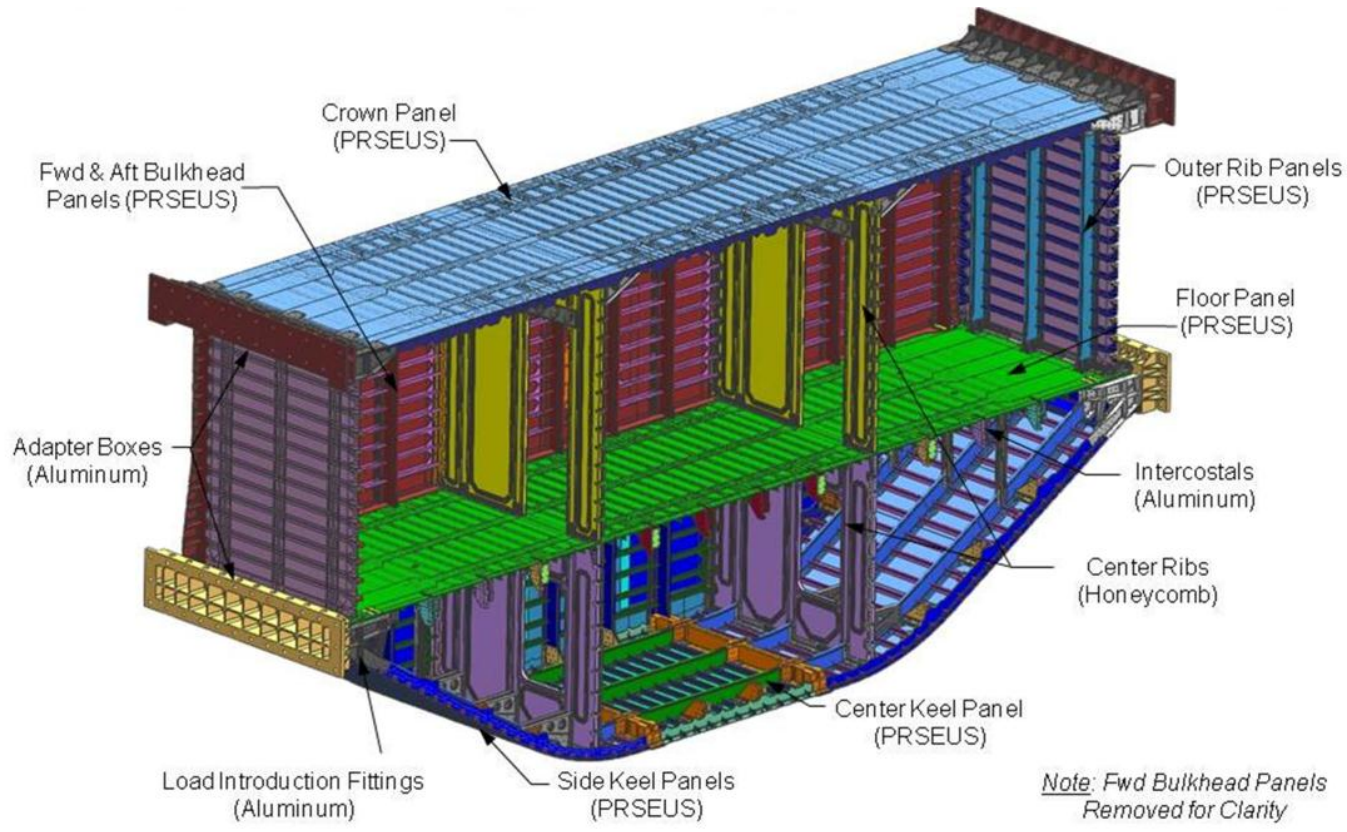

Figure 9. Multi-bay test article. 
The multi-bay test article contains 11 PRSEUS panels (cover, floor, two upper bulkhead, two lower bulkhead, two side rib, two side keel, lower keel), four honeycomb center rib panels, aluminum fittings and access doors, and titanium bolts. Based on the same design and manufacturing features as the cube test article, the double-deck, multi-bay box structure is built up using flat PRSEUS panels comprising integrally stitched stringer, frame, and cap features, that are then mechanically fastened to one another. The panel assemblies have nominal 24-inch frame pitch and 6-inch stringer spacing, with 0.052-inch thick skins in the center bay that gradually increase as they approach the concentrated loads imparted by the end fittings. Load continuity around the sharp corners of the individual bays is maintained using mechanically attached aluminum fittings and intercostals.

Strength and stability analyses were performed using a global finite element model created for linear static and linear buckling analyses. One-dimensional bar elements were used to model the combination of the pultruded rod and the stack that wraps around it. Two-dimensional shell elements were used in modeling skins, stringer flanges and webs, T-section caps, frame webs, and aluminum fittings. Onedimensional bar elements were also used at the frame cap locations to simulate the frame cap stiffness. Titanium fasteners were modeled with special MSC Nastran CFAST fastener connector elements. There are a total of 693,045 nodes, 676,718 elements, and 18,517 fastener connector elements in the global FEM, including the load introduction platens and boundary conditions. The finite element model is shown in figure 10 .

Five critical load cases were considered: $2.5 \mathrm{~g}, 2.5 \mathrm{~g}$ plus $1 \mathrm{P},-1.0 \mathrm{~g}$, and $-1.0 \mathrm{~g}$ plus $1 \mathrm{P}$ maneuver conditions, as well as the static $2 \mathrm{P}$ ground condition to size the overall test article structure. The limit load displacements for the critical 2.5g plus 1P load case are shown plotted in figure 11. Although the maximum displacements occur in the center of the outer bay pressure bulkheads, the critical region will be the center of the upper crown panel where the deflected panel must also simultaneously carry spanwise compressive loads, and is thus susceptible to general panel buckling. This condition is the critical nonlinear loading regime that forms the basis for the combined loads testing.

The multi-bay test article was designed to support $2 \mathrm{P}$ static proof load case where an interior pressure load of 18.4 psi must be maintained. The flight conditions of the $2.5 \mathrm{~g}$ and $-1.0 \mathrm{~g}$ load cases where the wing bending loads induce load into the test article can be simulated by applying loads on the end plates of structure through rigid end platens that are rotated about the specimen mid plane (slightly above the test article floor). For the critical $2.5 \mathrm{~g}$ maneuver, the center bay of the crown panel reaches an average running load of $-5,000$ lbs/inch across its width, which correlates to the test results of the compression panel subcomponent.

The test article is currently being constructed by The Boeing Company at their stitching center in Huntington Beach, CA. The fabrication sequence for the crown panel is outlined in figures 12-18.

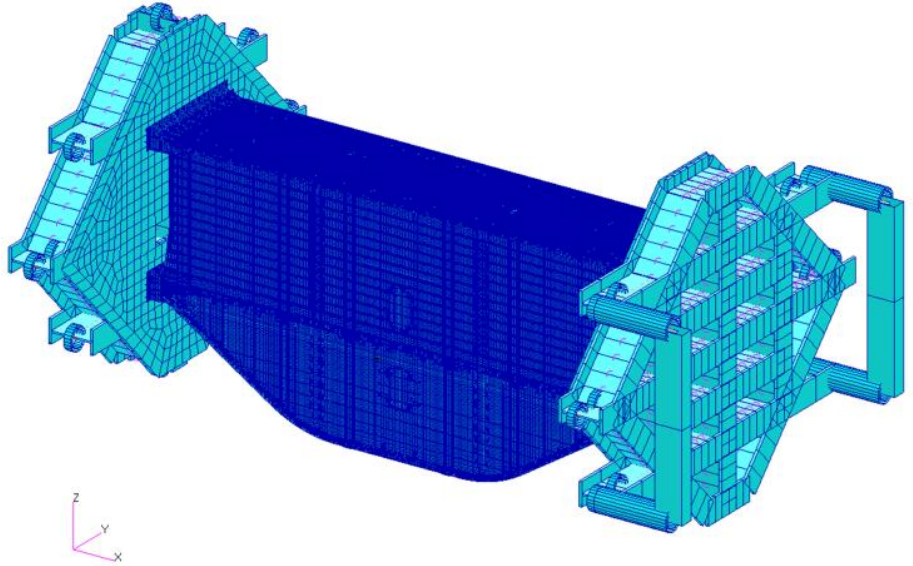

Figure 10. Multi-bay test article finite element model.

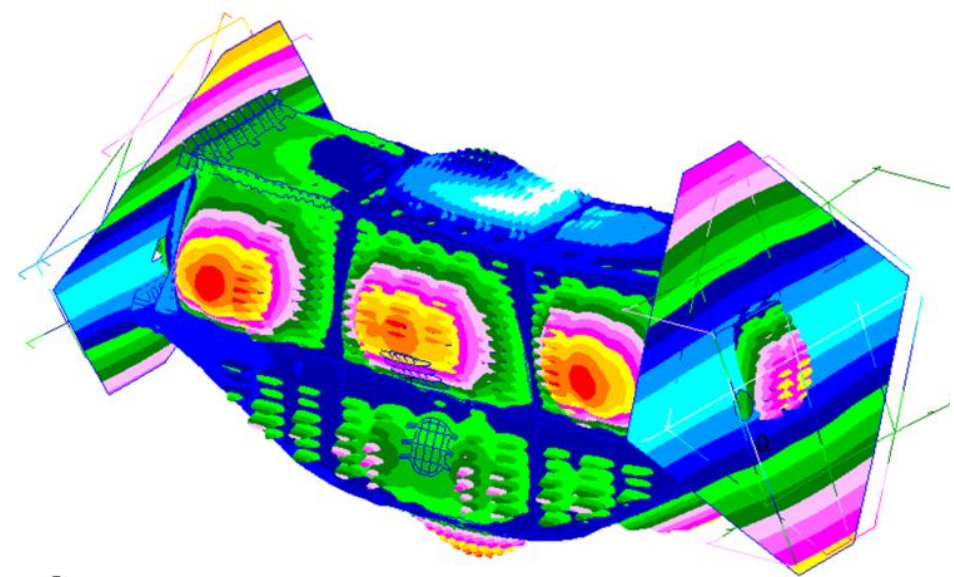

Figure 11. Multi-bay test article displacements at limit load for the $2.5 \mathrm{~g}$ plus $1 \mathrm{P}$ condition. 
The PRSEUS integrated panel assemblies are a collection of stitched preforms that are initially built in the dry state and then accurately net-molded in an oven cure operation using high-precision outer moldline tooling. The assembly of the dry preform starts with the cutting of individual pieces of warp-knit fabric on a cutting table, which are then organized into kits. Pre-cured rods and foam-core details are also prepared and in some cases, assembled into smaller pre-stitched assemblies. All of these details are then delivered to the preform assembly fixture where they are properly positioned (figure 12) and then stitched in place (figure 13).

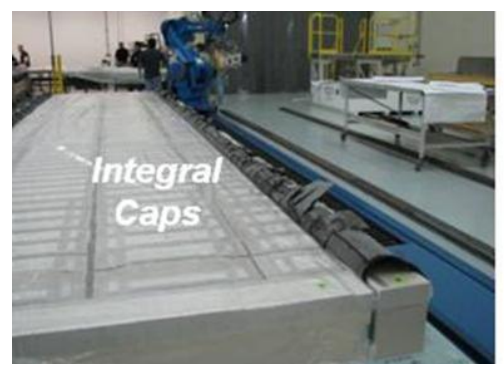

a) Integral caps

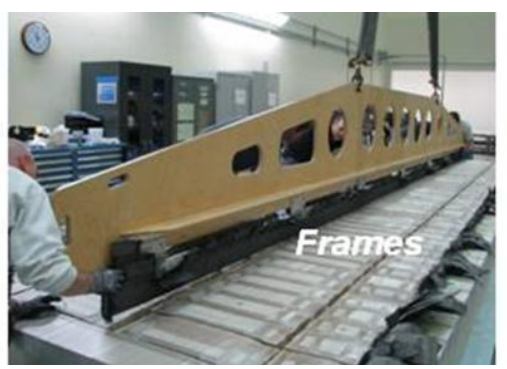

b) Frames

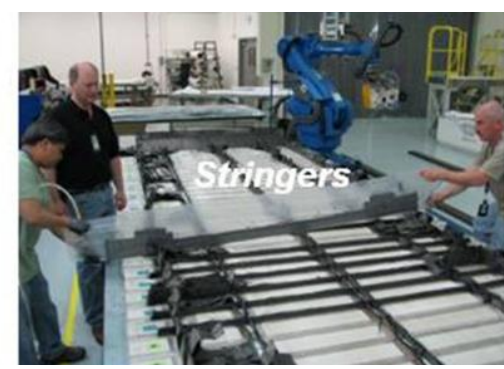

C) Stringers

Figure 12. Stiffener details loaded into crown panel preform assembly fixture.

The preform assembly tooling elements are accurately machined details that are indexed to a common steel base. The details are designed to fall away from the base once the stitch tool is rotated onto the cure tool. Each panel requires a specific set of blocks to accommodate the different panel configurations. The initial set up for the crown panel configuration is shown in figure 13 as the single-sided stitching operation was started.

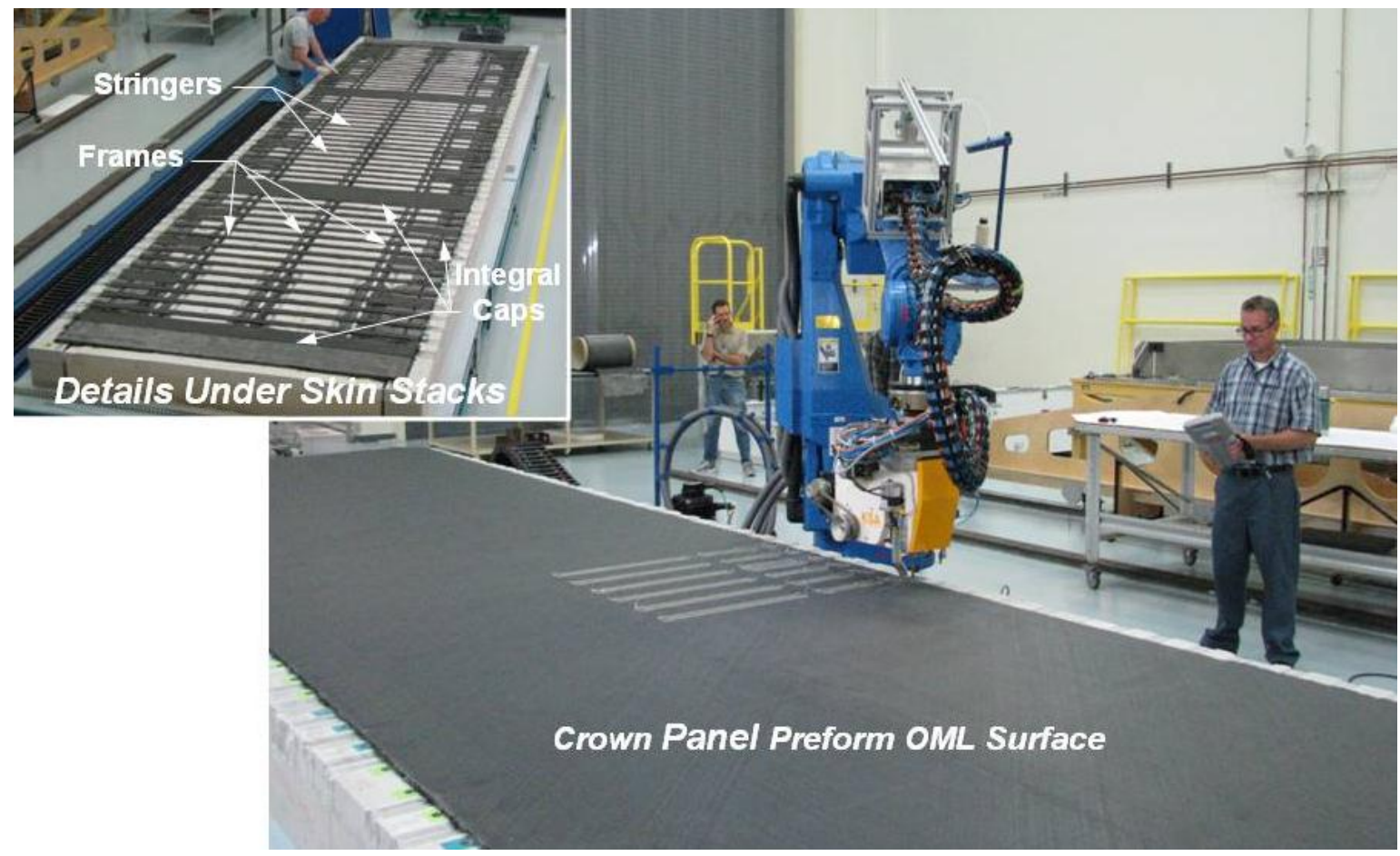

Figure 13. Single-sided stitching of crown panel preform.

Once the stitching operation was completed, the preform was then transferred to an outer mold line cure tool for resin infusion processing. This transfer was accomplished by strapping the dry preform to the preform assembly tool and rotating it into position onto the cure tool as shown in the steps in figure 14. 


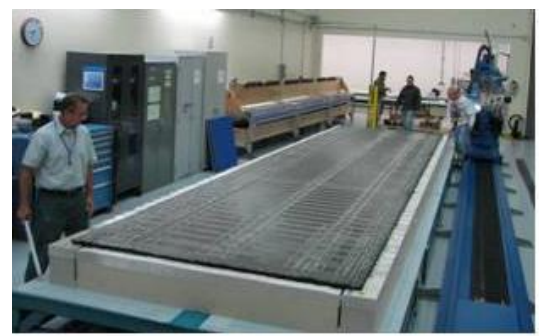

a) Preform on stitch tool

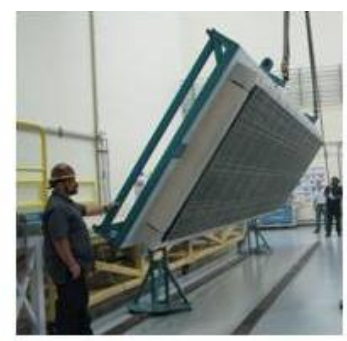

b) Flipping preform

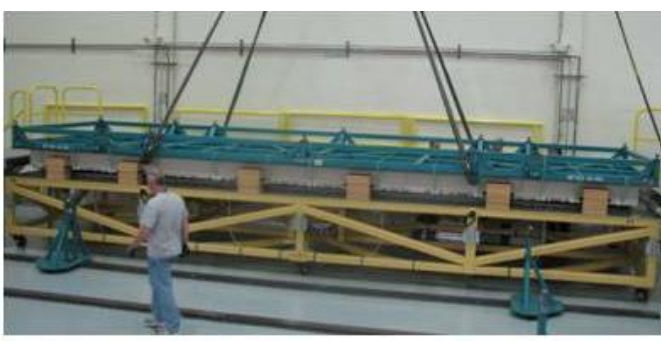

c) Preform set on OML tool

Figure 14. Preform transfer from stitch to cure tool.

When the steel base was detached, access to the interior tooling pieces was possible. These details were removed to expose the self-supporting preform lying on the cure tool as shown in figure 15a. Next, the under-bag tooling details were placed over the preform and indexed to the cure tool as shown in figure $15 \mathrm{~b}$. These tooling details are necessary to accurately net-mold key features and station planes for the integral cap features.

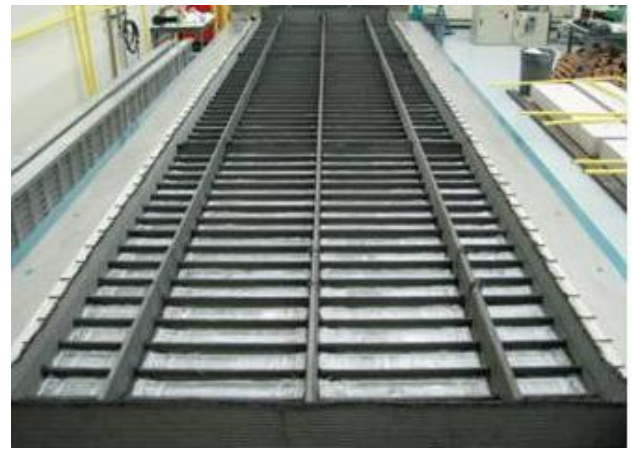

a) Self-supporting preform

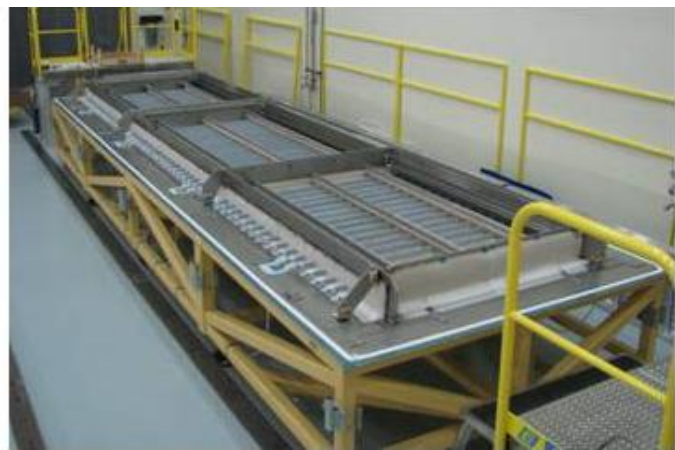

b) Preform within cure tooling

Figure 15. Stitched crown panel.

A pleated nylon vacuum bag system was then placed over the preform and sealed down against the cure tool edges. The preform was infused using the Boeing-patented CAPRI out-of-autoclave process with a Hexcel two-component amine cured epoxy system known as HEXFLOW VRM34. Resin inlet ports and distribution channels were integrally machined into the cure tool surface to feed flow media that rapidly disperses resin and a peel ply was used to separate the flow media from the preform. The preform was infused at $140^{\circ} \mathrm{F}$ and cured at $200^{\circ} \mathrm{F}$. The bagging system and resin lines were then removed and the part was placed back in the oven for a final free-standing post-cure at $350^{\circ} \mathrm{F}$. The bagged panel and the cured part are shown in figures $16 \mathrm{a}$ and $16 \mathrm{~b}$, respectively.

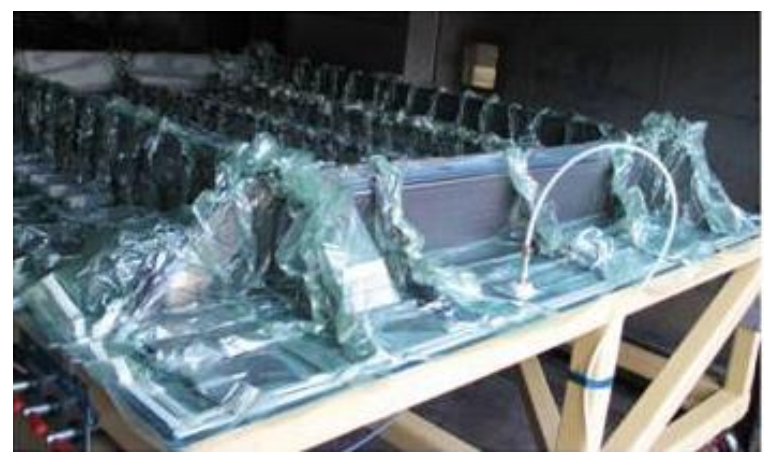

a) Bagged panel

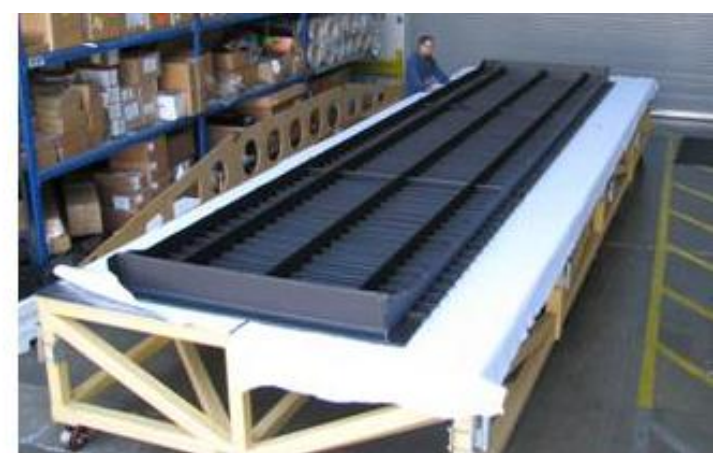

b) Cured panel

Figure 16. Bagged panel after infusion and cured panel with bag removed. 
Once cured, the panel was ready for the final machining operation, where a 1 -inch trim was removed along the panel perimeter, and the upstanding leg of the integral cap features were cut down to their final height and shape profile. The 30-foot-long crown panel was the largest PRSEUS panel fabricated to date and demonstrated the scale-up potential of PRSEUS structures.

Some of the key as-molded features of the one-piece crown panel assembly are shown in figure 17 prior to the final trim operation. Features such as the keyhole to allow the stringer to pass through the frame with minimal disruption in load path, the easily-performed variation in thickness in skin and flanges, the accuracy of the stiffener's straightness and position despite the fabrication being out of the autoclave and using bags for interior curing rather than hard metal tooling all demonstrate the viability of the highly integrated PRSEUS design and manufacturing approach.

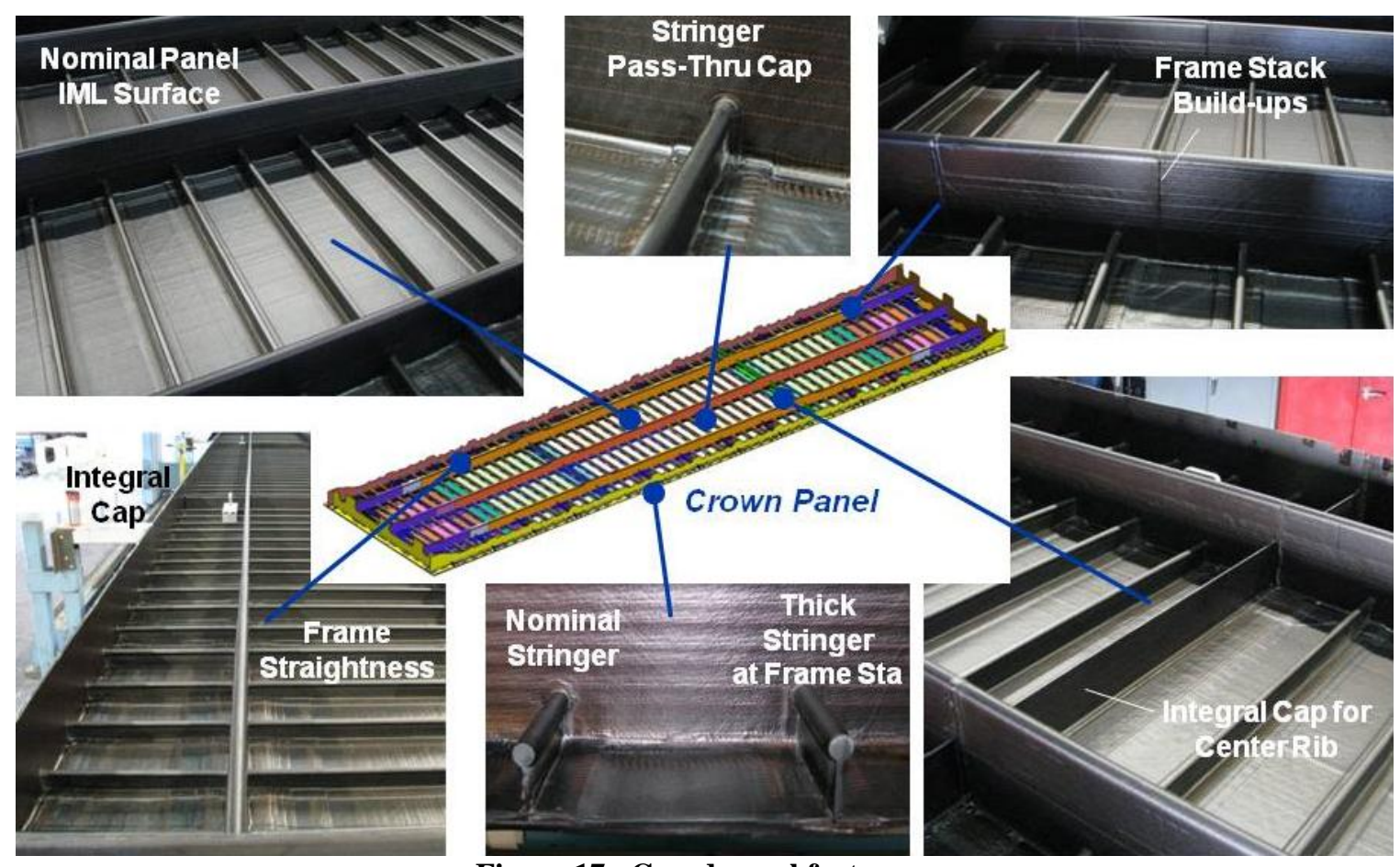

Figure 17. Cured panel features.

The stitching and infusion work for the remaining panels will continue through 2013 before enough cured panels are ready to start assembling the box structure in 2014, which will then be followed by testing in 2015. The general status of the panel fabrication effort is depicted in figure 18. The crown and floor panels are complete, the center rib sandwich panels are having their skins bonded, the two outer rib panels are stitched, and all of the remaining panel details have been cut and kitted waiting for their turn on the stitching tool. 


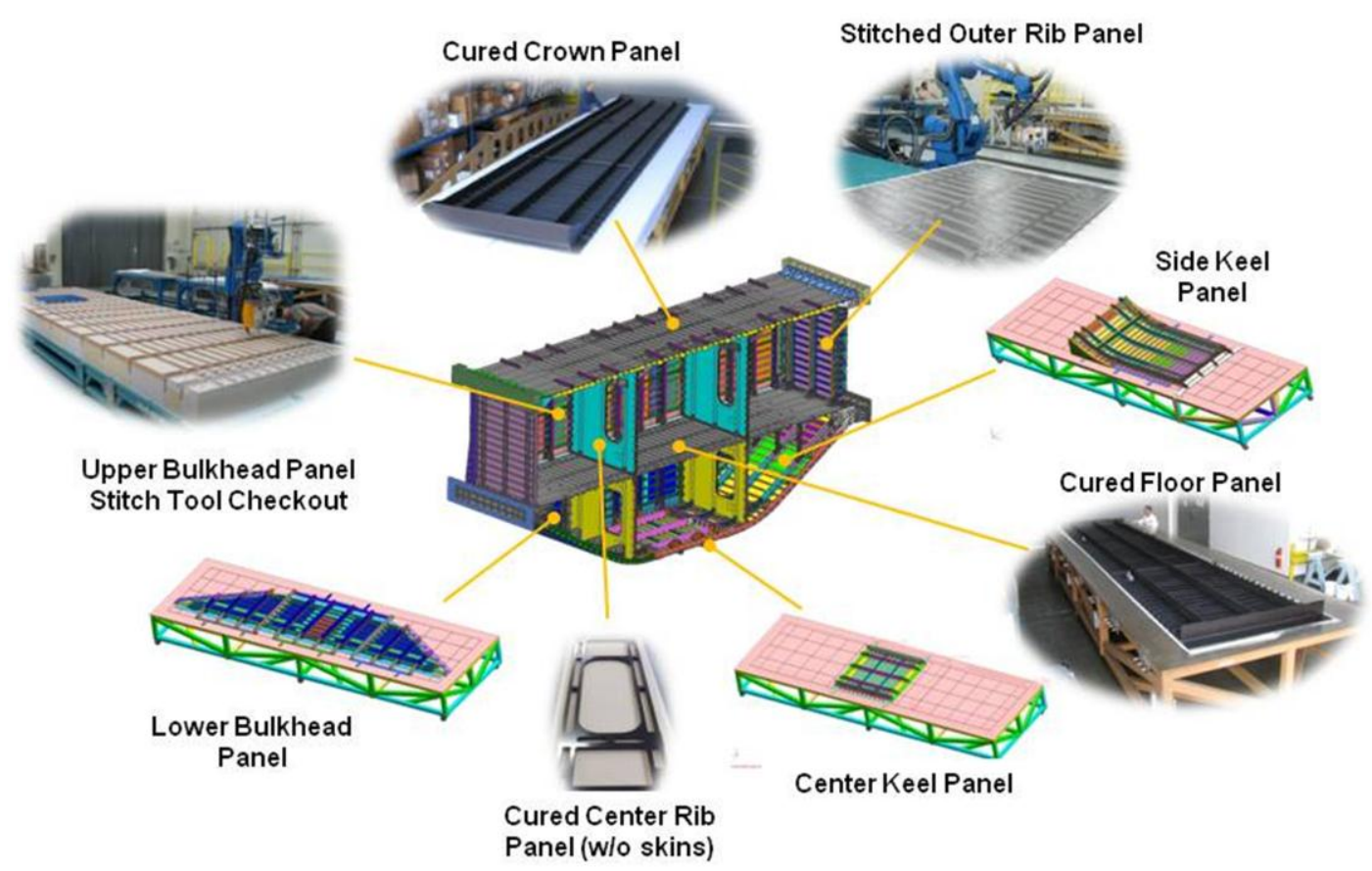

Figure 18. Multi-bay test article panel fabrication progress.

Once assembled, the test article will be shipped to the NASA Langley Research Center and loaded in a series of tests in the NASA Combined Loads Test System (COLTS), as shown in figure 19. If the test article performs as expected, at the conclusion of this series of tests, the multi-bay results will show that PRSEUS is capable of meeting the stringent weight goals established by the ERA program for the HWB airframe.

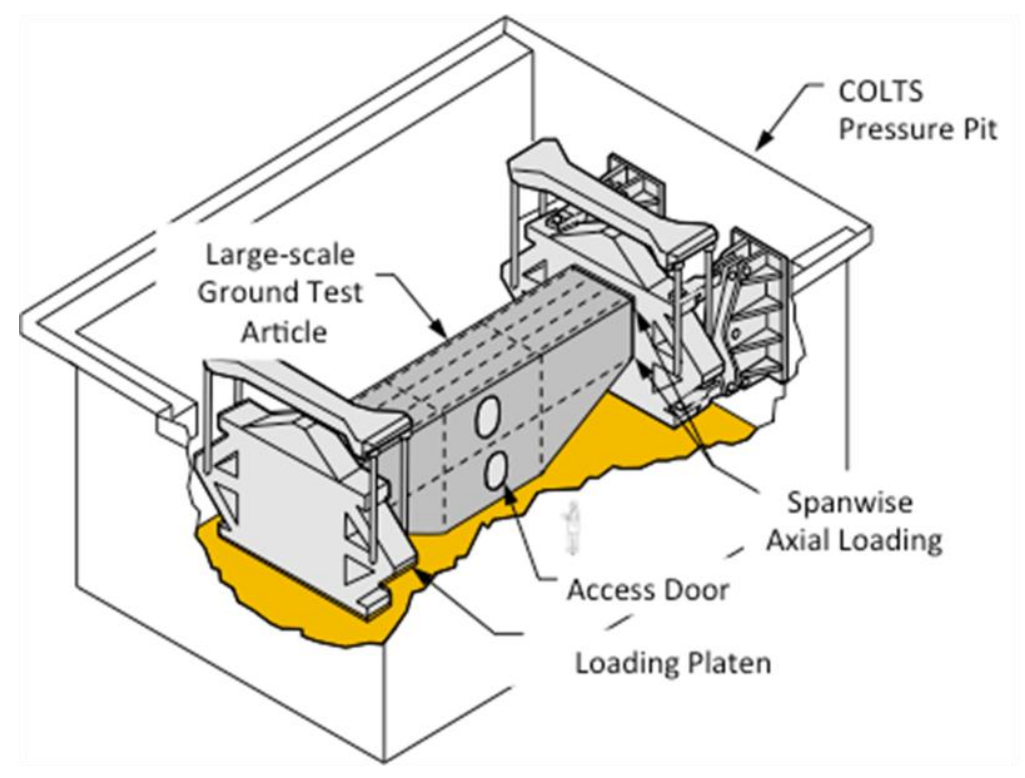

Figure 19. Multi-bay test article in COLTS. 


\section{Concluding Remarks}

The PRSEUS program demonstrates the advantages of stitched non-autoclaved unitized structure. PRSEUS is applicable to almost any large aircraft structure but is particularly valuable to the HWB center section. The focus of this study has been the hybrid wing body configuration which represents an opportunity to move beyond incremental airplane performance improvements by radically reshaping the aircraft centerbody to achieve first order aerodynamic improvements in lift-drag ratio. The success of such an approach rests squarely on the development of an advanced structural concept that is capable of offsetting the structural weight and cost penalties inherent in the non-circular centerbody design. To meet these challenges, researchers at NASA and The Boeing Company have developed a highly engineered structural solution that moves beyond traditional composite design practices to offer a highly efficient structural solution that can be operated substantially beyond conventional no-growth design techniques and limitations. The result is a very efficient airframe structure that combines the skin, stringers, and frame elements into an integral structural solution for reacting the complex combined loading of the HWB airframe. This unique approach represents a bold vision in composite design theory and oven-cure manufacturing methods. It is a departure from conventional multi-detail laminated and bonded/bolted composite assembly practices, and is an evolution toward larger, one-piece, cocured panel designs with seamless transitions and stitched interfaces. Characterization of this innovative approach to airframe shaping and structural concept development is the primary objective of the coordinated research work being performed by NASA and Boeing researchers under the structures portion of the NASA Environmentally Responsible Aviation initiative.

\section{References}

\footnotetext{
${ }^{1}$ Hoffman, K., Air Vehicle Technology Integration Program (AVTIP), Delivery Order 0059, "Multi-role Bomber Structural Analysis," AFRL-VA-WP-TR-2006-3067, May 2006, Final Report for 14 December 2004 - 08 May 2006.

${ }^{2}$ Velicki, A., and Thrash P.J., "Advanced Structural Concept Development Using Stitched Composites," 49th AIAA/ASME/ASCE/AHS/ASC Structures, Structural Dynamics, and Materials Conference, paper number AIAA2008-2329, June 2008, Schaumburg, IL.

3 Velicki, A., "Damage Arresting Composites for Shaped Vehicles - Phase I Final Report", NASA/CR-20091-215932, September 2009, Final Report for October 2007 - September 2008, contract number NNL07AA48A.

${ }^{4}$ Velicki, A., Yovanof, N., Baraja, J., Linton, K., Li, V., Hawley, A., Thrash, P., DeCoux, S., and Pickell, R., "Damage Arresting Composites for Shaped Vehicles - Phase II Final Report," NASA/CR-2011-216880, January 2011, Final Report for October 2008 - September 2010, contract number NNL07AA48A.

5 Jegley, D., "Influence of Impact Damage on Carbon-Epoxy Stiffener Crippling," American Society for Composites Conference, Dayton, OH, Oct. 2010.

${ }^{6}$ Wang, J., Grenoble, R., and Pickell, R., "Structural Integrity Testing Method for PRSEUS Rod-Wrap Stringer Design," Proceedings of the 53rd AIAA/ASME/ASCE/AHS/ASC Structures, Structural Dynamics and Materials Conference, Honolulu, HI, April, 2012.

${ }^{7}$ Lovejoy, A., Rouse, M., Linton, K., and Li, V., "Pressure Testing of a Minimum Gauge PRSEUS Panel," 52nd AIAA Structures Dynamics and Materials Conference, paper number AIAA-2011-1813, April 2011, Denver, CO.

${ }^{8}$ Yovanof, N., and Jegley, D., "Compressive Behavior of Frame-Stiffened Composite Panels," 52nd AIAA Structures Dynamics and Materials Conference, paper number AIAA-2011-1913, April 2011, Denver, CO.

${ }^{9}$ Przekop, A., "Repair Concepts as Design Constraints of a Stiffened Composite PRSEUS Panel," Proceedings of the 53rd AIAA/ASME/ASCE/AHS/ASC Structures, Structural Dynamics and Materials Conference, Honolulu, HI, April, 2012.

${ }^{10}$ Allen, A., and Przekop, A., "Vibroacoustic Characterization Of A New Hybrid Wing-Body Fuselage Concept," Internoise 2012/ASME NCAD Meeting, New York City, NY. August, 2012.

11 Linton, K., Neal, A., Mills, G., Velicki, A., and Thrash, P. (2011), "Design, Analysis, and Fabrication of a Curved PRSEUS Panel." Final report for NASA contract: NNL04AA11B/task order: NNL10AA99T, December 2010.

${ }^{12}$ Bergan, A., Bakuckas, J., Jr., Lovejoy, A., Jegley, D., Neal' A., Linton, K., Korkosz, G., Awerbuch, J., and Tan, T., "Full-Scale Test and Analysis Results of a PRSEUS Fuselage Panel to Assess Damage-Containment Features," 2012 Airworthiness and Sustainment Conference, April, 2012, Baltimore, MD.

${ }^{13}$ Yovanof, N., Lovejoy, A., Baraja, J., and Gould, K., "Design, Analysis and Testing of a PRSEUS Pressure Cube to Investigate Assembly Joints," 2012 Airworthiness and Sustainment Conference, April, 2012, Baltimore, MD.
} 